\title{
Early Childhood Assessments of Community Pediatric Professionals Predict Autism Spectrum and Attention Deficit Hyperactivity Problems
}

\author{
Merlijne Jaspers • Andrea F. de Winter • \\ Jan K. Buitelaar • Frank C. Verhulst • \\ Sijmen A. Reijneveld • Catharina A. Hartman
}

Published online: 12 June 2012

(C) The Author(s) 2012. This article is published with open access at Springerlink.com

\begin{abstract}
For clinically referred children with Autism Spectrum Disorder (ASD) or Attention Deficit/Hyperactivity Disorder (ADHD) several early indicators have been described. However, knowledge is lacking on early markers of less severe variants of ASD and ADHD from the general population. The aim of the present study is to identify early indicators of high risk groups for ASD and ADHD problems based on routine data from community pediatric services between infancy and age four. Data are from 1,816 participants who take part in Tracking Adolescents' Individual Lives Survey (TRAILS), a longitudinal study. Information on early developmental factors was extracted from charts of
\end{abstract}

Financial support TRAILS has been financially supported by various grants from the Netherlands Organization for Scientific Research (NWO), Social Sciences Council, the Sophia Foundation for Medical Research, the Dutch Ministry of Justice, and the participating universities.

M. Jaspers $(\bowtie) \cdot$ A. F. de Winter $\cdot$ S. A. Reijneveld

Department of Health Sciences, University Medical Center

Groningen, University of Groningen,

P.O. Box 196, 9700 AD, Groningen, The Netherlands

e-mail: m.jaspers@rug.nl

\section{J. K. Buitelaar}

Department of Psychiatry, Radboud University Nijmegen Medical Centre, Academic Center of Child and Adolescent Psychiatry,

Nijmegen, The Netherlands

F. C. Verhulst

Department of Child and Adolescent Psychiatry,

Erasmus MC-Sophia Children's Hospital,

Rotterdam, The Netherlands

\section{A. Hartman}

Department of Psychiatry, University Medical Center Groningen, University of Groningen,

Groningen, The Netherlands routine Preventive Child Healthcare ( $\mathrm{PCH}$ ) visits. To assess ASD and ADHD problems, respectively, we used the Children's Social Behavior Questionnaire (CSBQ) and the Child Behavior Checklist (CBCL), filled out by parents three times between the ages of 11 and 17 . Note that these are parent ratings and not diagnostic instruments performed by trained clinicians. Male gender, low birth weight, low level of education of the mother, social, behavioral, language, psychomotor and eating problems significantly predicted ASD problems (odds ratios (OR) between 1.34 and 2.41). ADHD problems were also predicted by male gender and low level of education of the mother and by maternal smoking during pregnancy, good gross motor skills in first year, early attention and hyperactivity problems, and absence of parent-reported positive behavior (ORs between 1.36 and 1.74). Routine data on early childhood from $\mathrm{PCH}$ services are predictive for ASD and ADHD problems in adolescents in the general population. The $\mathrm{PCH}$ services are a useful setting to identify high risk groups, and to monitor them subsequently.

Keywords Autism $\cdot$ ADHD $\cdot$ Risk factors $\cdot$ Longitudinal studies $\cdot$ Child development

$\begin{array}{ll}\text { Abbreviations } \\ \text { ADHD } & \text { Attention Deficit/Hyperactivity Disorder } \\ \text { ASD } & \text { Autism Spectrum Disorders } \\ \text { CBCL } & \text { Child Behavior Checklist } \\ \text { CSBQ } & \text { Children's Social Behavior Questionnaire } \\ \text { OR } & \text { Odds Ratios } \\ \text { PCH } & \text { Preventive Child Healthcare } \\ \text { TRAILS } & \text { Tracking Adolescents' Individual Lives Survey }\end{array}$




\section{Introduction}

Autistic spectrum disorders (ASD) and Attention Deficit/ Hyperactivity Disorder (ADHD) are neurodevelopmental disorders with an onset early in life, with a prevalence of around $1 \%$ and $5 \%$, respectively (St Pourcain et al. 2011; Rommelse et al. 2011). ASD and ADHD often co-exist. Estimates on overlap in children with ASD range from $28 \%$ to $53 \%$; ASD problems in children diagnosed with ADHD are also very common, although precise estimates are lacking (Hattori et al. 2006; Nijmeijer et al. 2010; St Pourcain et al. 2011; Reiersen et al. 2007; Rommelse et al. 2011; Ronald et al. 2010; Simonoff et al. 2008). A recent study showed that a complex longitudinal pattern exists between social-communication and hyperactivity-inattentive traits. The majority of children with persistent hyperactiveinattentive symptoms also showed persistent socialcommunication deficits but not vice versa (St Pourcain et al. 2011). Recently the field has broadened its focus so that it now views ASD and ADHD as constituting the very severe end of continuous distributions in the general population (Constantino and Todd, 2005; Levy et al. 1997; Stilp et al. 2010). Less severe variants of ASD and ADHD below the threshold for a diagnosis seem common, as shown by both family studies and studies in the general population (Constantino and Todd, 2005; Levy et al. 1997; Losh et al. 2009; Thapar et al. 2001). We further denote these as ASD and ADHD problems. Individuals with these subthreshold problems have similar but milder impairments in social functioning, communication, and information processing relative to children with a clinical diagnosis (Constantino and Todd, 2005; Hartman et al. 2012; Losh et al. 2009; Piven, 2002; Thapar et al. 2001). Thus, even at subthreshold level, problems may be an important burden for the children themselves, their parents, and others in their environment which may be alleviated by treatment.

Research has shown that early identification of ASD and ADHD, if followed by adequate intervention, may improve prognosis (Rogers and Vismara, 2008; Salmeron, 2009; Yirmiya and Charman, 2010; Zwaigenbaum et al. 2009). It seems important to identify, monitor and, if necessary, intervene in these developmental problems as early as possible. Community pediatric services, such as those in the USA and Europe, are in a unique position for early identification of developmental problems in children. Early indicators are needed to monitor high risk groups (who very likely will develop additional problems or impairments), but there is a dearth of evidence on these in the general population. For clinically referred children with ASD or ADHD, however, several early indicators have been reported in the literature; these concern pre- and perinatal factors (Arnoudse-Moens et al. 2009; Courchesne, 2004; Kolevzon et al. 2007; Mouridsen et al. 2008; Ploeger et al. 2010; Schendel et al. 2009; Smidts and Oosterlaan, 2007), early behaviors and emotions (Hartley et al. 2008; Hirshfeld-Becker et al. 2002; Loe and Feldman, 2007; Ozonoff et al. 2010; Smidts and Oosterlaan, 2007; Zwaigenbaum et al. 2005), motor and speech problems (Hagberg et al. 2010; Landa and Garrett-Mayer, 2006; Loe et al. 2008) and on atypicalities in regulation functions including sleeping and eating (Goodlin-Jones et al. 2008; Sung et al. 2008; Werner and Dawson, 2005). The age of observation of these indicators varies, and fluctuates between 6 months and three-and-a-half years (Zwaigenbaum et al. 2005; Zwaigenbaum et al. 2009).

The aim of the present study is to identify early indicators of high risk groups for ASD and ADHD problems based on routine data from community pediatric services between infancy and age four. The present study is complementary to previous prospective work in that it is the first to focus on the general community by using data from routine Preventive Child Healthcare (PCH) measurements, and from birth up to age four. The presence of ASD and ADHD problems was assessed during (pre-) adolescence. Note that previous studies on early indicators were focused on either ASD or ADHD. Given frequent co-occurrence (Hattori et al. 2006; Nijmeijer et al. 2010; Reiersen et al. 2007; Rommelse et al. 2011; Simonoff et al. 2008) and evidence of overlapping early indicators when the separate literatures on ADHD and ASD are brought together, their simultaneous study may further our insight into which indicators are unique to these disorders and which might be viewed as generic indicators for both. For the purpose of early detection and treatment, this is highly relevant.

\section{Methods}

The TRacking Adolescents' Individual Lives Survey (TRAILS) is a prospective cohort study among Dutch (pre-)adolescents, beginning at 10-12 years of age, that focuses on adolescent psychosocial development and mental health in the general population (de Winter et al. 2005; Huisman et al. 2008). Of all the pre-adolescents approached for enrollment in the study $(n=3,145), 6.7 \%$ were excluded in case of mental (IQ $<60$ based on school information) or physical incapability, or if no Dutch-speaking parent or parent surrogate was available. Seventy-six percent of the remaining 2935 pre-adolescents and their parents agreed to participate. The present study involves data from the first $(\mathrm{n}=2,230$; mean age $=11,09 ; \mathrm{SD}=0.56$; starting March 2001), second $(n=2,149$, mean age $=13.55 \mathrm{SD}=0.54)$ and third waves $(n=1,819$, mean age $=16.26 \mathrm{SD}=0.73)$, and also involves data from the $\mathrm{PCH}$ files. Parents of 2,139 (96\%) children gave written informed consent to retrieve their child's file from the PCH at T1. Out of these, $84.9 \%$ could be traced ( $\mathrm{n}=1,816 \mathrm{PCH}$ files). Children with and without a 
PCH file differed in parent-rated ASD $(\mathrm{M}=5.45, \mathrm{SE}=0.13$ for the retrieved and $\mathrm{M}=7.25, \mathrm{SE}=0.36$ for the nonretrieved, $P<0.001$, i.e. higher scores among the nonretrieved) and ADHD problems $(\mathrm{M}=3.83, \mathrm{SE}=0.08 \mathrm{vs}$ $\mathrm{M}=4.41, \mathrm{SE}=0.19$, respectively, $P<0.01$ ) at $\mathrm{T} 1$. Both for ASD and ADHD problems, higher scores indicate more symptoms. The TRAILS study was approved by the national ethical committee 'Central Committee on Research involving Human Subjects'.

\section{The Outcome Measures: ASD and ADHD Problems}

Parents filled out the Children's Social Behavior Questionnaire (CSBQ) and the Child Behavior Checklist (CBCL) at all three measurement waves. The CSBQ is a validated questionnaire for child social problems typically seen in children with ASD, especially in its milder forms, for ages 4-18 (Hartman et al. 2006). The sum of the subscales of social interest, social understanding, stereotyped behavior, and resistance to change was used, which captures the core symptoms of ASD and consists of 30 items ('t HartKerkhoffs et al. 2009). The CBCL is an internationally validated questionnaire for child emotional and behavioral problems for ages 4-18 and consists of 118 items (Achenbach et al. 2003). From this questionnaire we used the DSM-IVoriented attention-hyperactivity problem scale as outcome measure. This scale consists of seven items.

\section{Early Indicators}

In the Netherlands, PCH services provide health and developmental monitoring for all Dutch children from birth until age 19; the participation rate is over $90 \%$. The information on indicators had been collected by community physicians and nurses (PCH professionals) as part of the routine procedure of the $\mathrm{PCH}$. These assessments included a general physical examination, standardized screening procedures and an interview with parents concerning health status and developmental (physical, emotional and behavioral) problems, which were all documented in the PCH file. An assessment takes approximately 10 to $15 \mathrm{~min}$. In accordance with the literature we selected all potentially relevant predictors: pre- and perinatal factors, BMI and head circumference growth curves, psychomotor factors, early childhood behaviors, and sociodemographic variables from the $\mathrm{PCH}$ file.

Pre- and Perinatal Variables

Pre- and perinatal variables concerned maternal smoking and alcohol use during pregnancy, low birth weight (registered in grams) and birth defects as provided by the obstetrician or midwife. Maternal smoking and alcohol use were assessed as: "Did the mother smoke during pregnancy?" and "Did the mother use alcohol during pregnancy?" These questions were part of the $\mathrm{PCH}$ files, but were also part of the T1 interview in TRAILS (when a child was age 11 years). If either answer was "yes," we defined a score as indicative of smoking or alcohol use, respectively. The obstetrician or midwife could report yes or no, and in case of yes the amount per week or day. Often only yes or no was filled out, so more detailed information on quantity could not be retrieved. Low birth weight was defined as $<2500$ grams, which is the standard clinical cut-off point. Birth defects included limb deformities, craniofacial malformations and anomalies in organs, which are often seen in children with a clinical diagnosis of autism (Ploeger et al. 2010). Respondents received a "yes" if any of these were present and a "no" if none were present.

\section{BMI and Head Circumference Increase}

BMI at age 2, 3 and 4 years (extracted from weight and height in the PCH files) was categorized into: low BMI, intermediate BMI and high BMI; gender and age-specific cut-offs were used (Cole et al. 2000; Cole et al. 2007). Head circumference increase, from birth until age six months and from age 6 months until 12 months, was standardized into Mean Z-scores (Courchesne et al. 2003), and then dichotomized into the highest $10 \%$ versus the rest.

\section{Psychomotor Development}

Psychomotor development from birth to age four was assessed by three indices. The first was the Van Wiechen Scheme designed for children aged between 1 month and 15 months, which is the Dutch equivalent of the Bayley scales (Jacobusse et al. 2006). The PCH professional assigns a pass or fail score to each indicator for a given child. Indicators are divided into three different subcategories: gross motor skills (16 items), fine motor skills and adaptation (11 items), and communication and social behavior (10 items); each is targeted at children of a certain age. Items within these three subcategories are summed to provide subscales.

The second index concerned psychomotor development from the age of 18 months until four years old, with six measurements in this period, and was assessed as: "Does the child have any problems with motor skills and/or with speech and language" with both reported by either a "yes" or "no". Motor skills, and speech and language, were each added up, respectively, and then dichotomized to a "yes" if any of these were present during these six occasions, and a "no" if none were present.

The third index concerned neurological problems observed during physical examination of the child, conducted 
six times between the ages of 18 months and 4 years old. If on any occasion a problem was present, this index was coded as "yes", and as "no" if none were present.

\section{Early Childhood Behavior}

Early childhood behavior refers to behavioral features which were the most striking in the child and were recorded between ages 1.5 to 4 years, for which we distinguished "sleeping, eating and emotional and behavioral problems." During PCH visits, the PCH professional inquired into these problems as: "How is your child doing as far as eating is concerned?" and "How is your child doing as far as sleeping is concerned?" Difficulties such as "has problems falling asleep", "wakes up and can't sleep afterwards", "eats with much problems" or "eats very little" were reported. Descriptions of these behaviors were categorized as "yes," in case of problems, and "no" or "missing." The responses to the six times that these behaviors were probed were added up, and then dichotomized to a "yes," if any of these were present, and a "no," if none were present. "Emotional and behavioral problems" were collected from three open questions in the PCH files, that is, "How does the child play," "How is the child's behavior?" and "How is the child's social behavior?" The community physician or the nurse could report difficulties here such as "overactive," "shy," "anxious" or "aggressive," but also strengths such as "social" (see Table 1). These PCH registered descriptions were categorized as social problems in behavior, attention hyperactivity problems, internalizing problems, externalizing problems or absence of parent-reported positive behavior and then dichotomized to a "yes" if any of these were present during these six occasions, and a "no" if none were present.

\section{Sociodemographic Variables}

Sociodemographic variables refer to the highest educational level of the father and the highest educational level of the mother. We have distinguished two groups here: low (lower tracks of secondary education or less), and middle and high (higher tracks of secondary education, and university degree or more) educational levels, respectively.

\section{Statistical Analysis}

Prior to analyses, both outcome measures (CSBQ and CBCL) were dichotomized. To determine the optimal cutoff point for dichotomization for both questionnaires, we plotted the cumulative score distribution of decentile scores (x-axis) versus raw scores (y-axis). All graphs showed steep increases in problem behavior with a consistent kink at the $80^{\text {th }}$ percentile. From that point onwards children began to have substantially more problems. For the CSBQ, the kink at the $80^{\text {th }}$ percentile was at 9 for all three measurements; for the ADHD scale of the CBCL it was 7. We defined a score above the 80th percentile at least twice (out of three measurements) as indicative of the presence of ASD and ADHD problems. Note that these questionnaires were not diagnostic tools performed by trained clinicians.

Subsequently we calculated descriptive statistics for all predictor variables and performed logistic regression analysis to examine the influence of early development on ASD and ADHD behaviors. Based on the results of the univariate analyses, we considered variables associated with the outcomes at $p<0.2$ to be candidates for multiple logistic regression analyses. Variables were entered into a backward stepwise logistic regression procedure, generating a subset of independent predictors for the two outcome measures. As a final step, we investigated whether our final multivariate models changed when we brought the presence of ASD problems into the equation for predicting ADHD problems and vice versa; this to determine whether identified indicators were generic or specific to these problems. Statistical analyses were performed using SPSS Windows version 16 .

\section{Results}

Out of our overall sample $(n=1,816), 348$ adolescents met the ASD criterion and 419 fulfilled the ADHD criterion. One hundred and ninety-six met both ASD and ADHD criteria. Descriptive statistics of predictor variables in the ASD and ADHD groups, as well as in the remainder of the total sample, i.e. those who are not in either the ASD or the ADHD group, are presented in Table 2. The Mean of the CSBQ was 5.5 at $\mathrm{T} 1(\mathrm{SD}=5.6), 5.1$ at $\mathrm{T} 2(\mathrm{SD}=5.8)$ and 5.0 at $\mathrm{T} 3(\mathrm{SD}=5.7)$. The Mean of the $\mathrm{CBCL}$ was 3.8 at $\mathrm{T} 1$ $(\mathrm{SD}=3.1), 2.8$ at $\mathrm{T} 2(\mathrm{SD}=2.7)$ and 2.5 at $\mathrm{T} 3(\mathrm{SD}=2.6)$.

Table 3 gives the crude and multivariate odds ratios (OR), and the $95 \%$ confidence intervals, on the predictors for ASD and ADHD problems on the CSBQ and the CBCL. Male gender, a low level of education of the mother, a low birth weight, language, psychomotor and eating problems, and social problems (all at toddler age) were identified as significant independent determinants of ASD problems on the CSBQ. A low level of education of the father, maternal smoking during pregnancy, head circumference increase (0-6 months), low BMI at age 2, sleep problems and absence of parent-reported positive behavior did not contribute to the model as independent predictors in multivariate analyses. Controlling for ADHD problems in the ASD group left the model virtually unchanged, only a low level of education of the mother dropped below significance levels, with small reductions in OR. The OR for the presence of ADHD problems was substantial (Table 3). 
Table 1 Description of behavior of children by PCH professionals divided into five categories

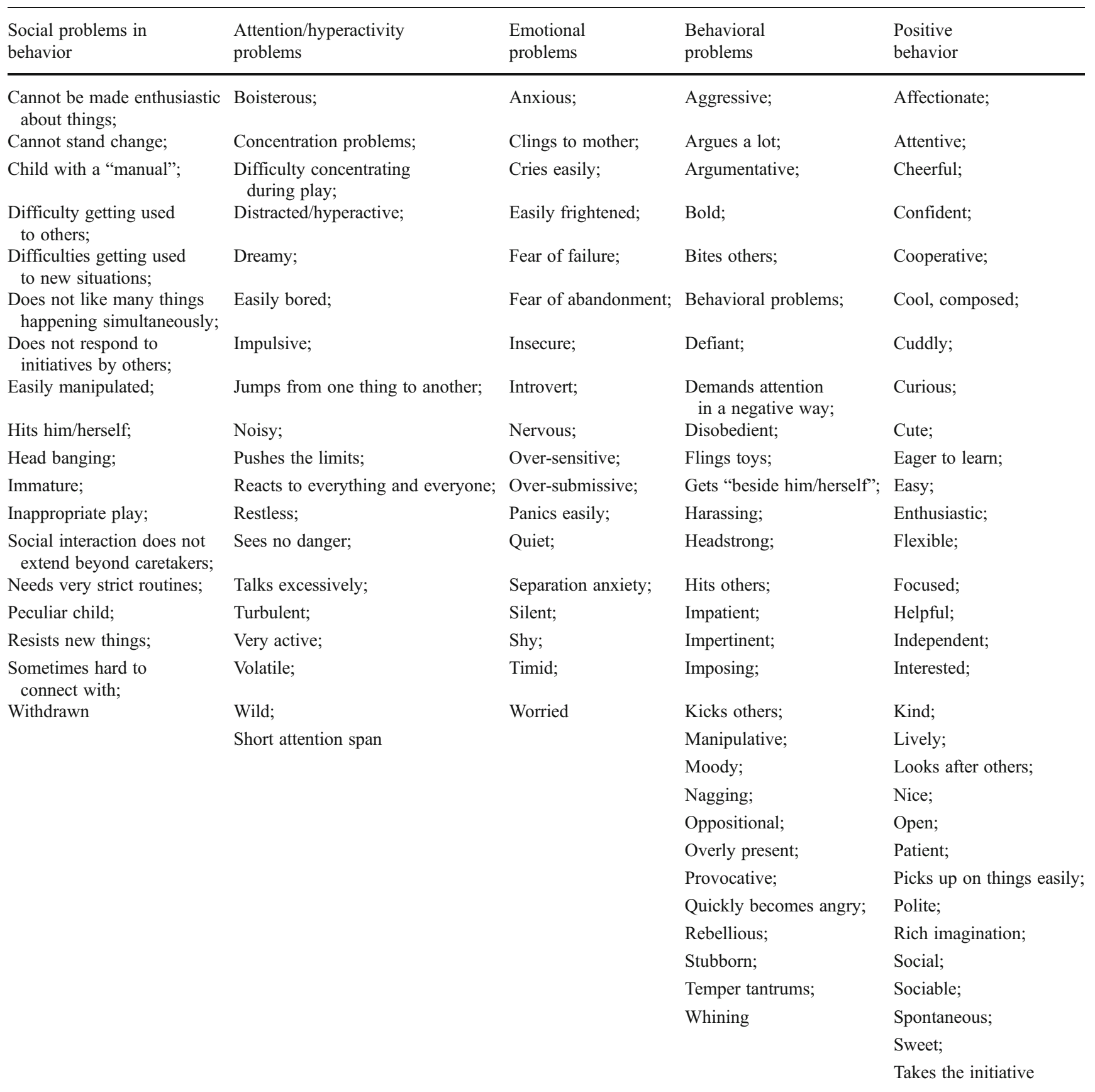

For ADHD problems on the CBCL, male gender, a low level of education of the mother, maternal smoking during pregnancy, gross motor skills (during the first year), attention hyperactivity problems, and absence of parent-reported positive behavior (at toddler age) were determinants. A low level of education of the father, sleep problems, problems with eating and externalizing problems did not contribute to the model as independent predictors in multivariate analyses. Controlling for ASD problems in the ADHD group left the model nearly intact; only maternal smoking during pregnancy and the absence of parent-reported positive behavior dropped below significance levels, with small reductions in ORs. The OR for the presence of ASD problems was substantial (Table 3).

\section{Discussion}

This study was the first to use early childhood findings as registered by community pediatric services to predict ASD 
Table 2 Scores on early indicators in Autism Spectrum Disorders (ASD) and Attention Deficit/Hyperactivity Disorder (ADHD) groups and the remaining of the sample

\begin{tabular}{|c|c|c|c|}
\hline Indicators from $\mathrm{PCH}$ file & $\begin{array}{l}\operatorname{ASD}^{\mathrm{a}} \\
\text { group } \mathrm{n}=348 \\
\mathrm{~N}(\%)\end{array}$ & $\begin{array}{l}\mathrm{ADHD}^{\mathrm{b}} \\
\text { group } \mathrm{n}=419 \\
\mathrm{~N}(\%)\end{array}$ & $\begin{array}{l}\text { Remaining of the } \\
\text { sample } n=1245 \\
N(\%)\end{array}$ \\
\hline Boys & $215(61.8 \%)$ & $253(60.4 \%)$ & $543(43.6 \%)$ \\
\hline Low education of mother & $141(40.5 \%)$ & $179(42.7 \%)$ & $332(34.2 \%)$ \\
\hline Low education of father & $110(31.6 \%)$ & $125(29.8 \%)$ & $339(27.2 \%)$ \\
\hline Maternal alcohol use during pregnancy & $66(19 \%)$ & $94(22.4 \%)$ & $247(19.8 \%)$ \\
\hline Maternal smoking during pregnancy & $124(35.6 \%)$ & $158(37.7 \%)$ & $365(29.3 \%)$ \\
\hline Low birth weight $(<2500$ grams $)$ & $26(7.5 \%)$ & $24(5.7 \%)$ & $60(4.8 \%)$ \\
\hline Birth defects & $7(2.0 \%)$ & $7(1.7 \%)$ & $27(2.2 \%)$ \\
\hline Neurological abnormalities (age $0-4$ yrs.) & $15(4.3 \%)$ & $25(6.0 \%)$ & $63(5.1 \%)$ \\
\hline Head circumference increase ( $0-6$ mos. $)$ & $39(11.2 \%)$ & $35(8.4 \%)$ & $94(7.6 \%)$ \\
\hline Head circumference increase (6-12 mos.) & $27(7.8 \%)$ & $25(6.0 \%)$ & $76(6.1 \%)$ \\
\hline Low BMI at age 2 & $45(12.9 \%)$ & $44(10.5 \%)$ & $143(11.5 \%)$ \\
\hline Low BMI at age 3 & $3(0.9 \%)$ & $8(1.91 \%)$ & $13(1.0 \%)$ \\
\hline Low BMI at age 4 & $2(0.6 \%)$ & $1(0.2 \%)$ & $15(1.2 \%)$ \\
\hline $\begin{array}{l}\text { Van Wiechen Scheme (VWS): gross } \\
\text { motor skills (age } 1-15 \text { mos.) }\end{array}$ & $72(20.7 \%)$ & $59(14.1 \%)$ & $261(21.0 \%)$ \\
\hline $\begin{array}{l}\text { VWS: fine motor skills and adaptation } \\
\text { (age } 1-15 \text { mos.) }\end{array}$ & $29(8.4 \%)$ & $26(6.2 \%)$ & $83(6.7 \%)$ \\
\hline $\begin{array}{l}\text { VWS: communication and social } \\
\text { behavior (age } 1-15 \text { mos.) }\end{array}$ & $30(8.6 \%)$ & $36(8.6 \%)$ & $81(6.5 \%)$ \\
\hline Language difficulties (age 1.5-4 yrs.) & $32(9.2 \%)$ & $30(7.2 \%)$ & $74(5.9 \%)$ \\
\hline Psychomotor difficulties (age 1.5-4 yrs.) & $25(7.2 \%)$ & $19(4.5 \%)$ & $44(3.5 \%)$ \\
\hline Sleep problems (age 1.5-4 yrs.) & $105(30.2 \%)$ & $126(30.1 \%)$ & $287(23.1 \%)$ \\
\hline Problems with eating (age 1.5-4 yrs.) & $196(56.3 \%)$ & $232(55.4 \%)$ & $604(48.5 \%)$ \\
\hline Social problems in behavior (age 1.5-4 yrs.) & $38(10.9 \%)$ & $35(8.4 \%)$ & $79(6.3 \%)$ \\
\hline Attention hyperactivity problems (1.5-4 yrs.) & $133(38.2 \%)$ & $203(48.4 \%)$ & $421(33.8 \%)$ \\
\hline Externalizing problems (age 1.5-4 yrs.) & $146(42.0 \%)$ & $190(45.3 \%)$ & $446(35.8 \%)$ \\
\hline Internalizing problems (age 1.5-4 yrs.) & $66(19.0 \%)$ & $64(15.3 \%)$ & $217(17.4 \%)$ \\
\hline $\begin{array}{l}\text { Absence of parent-reported positive } \\
\text { behavior (age } 1.5-4 \text { yrs.) }\end{array}$ & $176(50.6 \%)$ & $206(49.2 \%)$ & $507(40.7 \%)$ \\
\hline
\end{tabular}

and ADHD problems in adolescents in a large longitudinal community-based sample. We identified several early childhood indicators predictive of ASD and ADHD problems. Male gender and low level of education of the mother were generic indicators, while a low birth weight, social behavioral problems, language, and psychomotor and eating problems at toddler age were specific for ASD problems, and maternal smoking during pregnancy, gross motor skills during infancy, and attention hyperactivity problems at toddler age, for ADHD problems.

We found two important results that warrant further comment. Both controlling for ADHD problems in the ASD group and controlling for ASD problems for the ADHD group did leave the model virtually unchanged and vice versa, while the OR for the presence of ASD and ADHD problems was substantial. This indicates that neither risk indicators for ASD nor risk indicators for ADHD can be attributed solely to the shared variance between ADHD and ASD, therefore, early developmental risk indicators are to some extent specific for ASD and ADHD.
A second intriguing result was that early attention and hyperactivity problems were predictive for later ADHD problems but not ASD problems while early social problems in behavior were predictive for later ASD problems but not ADHD problems. In contrast, during adolescence ADHD is predictive for ASD and vice versa (St Pourcain et al. 2011). This finding points to specificity of risk indicators measured very early in development.

Our study adds important information because our approach uses $\mathrm{PCH}$ data in the general community which differs from previous studies on early indicators of ASD or ADHD. Previous studies on ASD focused on clinicallyreferred and selective high-risk children, such as siblings of children with ASD (Goodlin-Jones et al. 2008; Landa and Garrett-Mayer, 2006; Ozonoff et al. 2010). Previous studies about early indicators of ADHD are scarce, and none of them was based on prospectively collected data to a younger age than 2 years (Loe et al. 2008; Smidts and Oosterlaan, 2007). The few population studies on early risk indicators of 
Table 3 Associations of Preventive Child Healthcare indicators with Autism Spectrum Disorders (ASD) and Attention Deficit/Hyperactivity Disorder (ADHD) problems: odds ratios (OR) and $95 \%$ confidence intervals (CI)

\begin{tabular}{|c|c|c|c|c|c|c|}
\hline & \multicolumn{3}{|l|}{ ASD group $N=348$} & \multicolumn{3}{|c|}{ ADHD group $N=419$} \\
\hline & $\begin{array}{l}\text { OR (crude) } \\
95 \% \mathrm{CI}\end{array}$ & $\begin{array}{l}\text { OR (adj) } \\
95 \% \text { CI }\end{array}$ & $\begin{array}{l}\text { OR (adj) } \\
95 \% \text { CI }\end{array}$ & $\begin{array}{l}\text { OR (crude) } \\
95 \% \mathrm{CI}\end{array}$ & $\begin{array}{l}\text { OR (adj) } \\
95 \% \text { CI }\end{array}$ & $\begin{array}{l}\text { OR (adj) }{ }^{b} \\
95 \% \text { CI }\end{array}$ \\
\hline Boys & $1.71(1.39-2.11)$ & $1.87(1.43-2.45)$ & $1.63(1.27-2.17)$ & $1.75(1.43-2.13)$ & 1.74 (1.38-2.19) & $1.41(1.08-1.85)$ \\
\hline $\begin{array}{l}\text { Low education } \\
\text { of mother }\end{array}$ & $1.65(1.28-2.13)$ & $1.45(1.12-2.11)$ & $1.40(0.96-2.03)$ & $1.74(1.37-2.21)$ & $1.52(1.15-2.01)$ & $1.45(1.01-2.08)$ \\
\hline Low education of father & $1.48(1.15-1.90)$ & & & $1.59(1.25-2.02)$ & & \\
\hline $\begin{array}{l}\text { Maternal alcohol use } \\
\text { during pregnancy }\end{array}$ & $0.96(0.74-1.24)$ & & & $1.10(0.86-1.40)$ & & \\
\hline $\begin{array}{l}\text { Maternal smoking } \\
\text { during pregnancy }\end{array}$ & $1.24(1.01-1.54)$ & & & $1.60(1.30-1.96)$ & $1.36(1.07-1.73)$ & $1.31(0.99-1.75)$ \\
\hline Low birth weight & $1.67(1.05-2.67)$ & $1.93(1.14-3.27)$ & $1.95(1.10-3.48)$ & $1.13(0.70-1.82)$ & & \\
\hline Birth defects & $0.97(0.42-2.24)$ & & & $0.75(0.33-1.72)$ & & \\
\hline $\begin{array}{l}\text { Neurological } \\
\text { abnormalities }\end{array}$ & $0.78(0.45-1.38)$ & & & $1.22(0.76-1.96)$ & & \\
\hline $\begin{array}{l}\text { Head circumference } \\
\text { increase }(0-6 \text { mos. })\end{array}$ & $1.50(1.04-2.26)$ & & & $0.91(0.61-1.35)$ & & \\
\hline $\begin{array}{l}\text { Head circumference } \\
\text { increase }(6-12 \text { mos. })\end{array}$ & $1.38(0.88-2.12)$ & & & $1.07(0.50-2.31)$ & & \\
\hline Low BMI at age 2 & $1.54(1.10-2.20)$ & & & $1.03(0.74-1.44)$ & & \\
\hline Low BMI at age 3 & $1.07(1.01-1.14)$ & & & $2.59(0.94-7.13)$ & & \\
\hline Low BMI at age 4 & $0.66(0.13-3.48)$ & & & $0.24(0.03-2.05)$ & & \\
\hline $\begin{array}{l}\text { Van Wiechen Scheme } \\
\text { gross motor skills }\end{array}$ & $0.94(0.70-1.25)$ & & & $0.73(0.61-0.88)$ & $0.59(0.44-0.80)$ & $0.60(0.42-0.87)$ \\
\hline VWS fine motor skills & $1.30(0.85-2.01)$ & & & $0.88(0.56-1.38)$ & & \\
\hline VWS communication & $1.27(0.83-1.94)$ & & & $1.28(0.86-1.91)$ & & \\
\hline Language difficulties & $1.61(1.05-2.46)$ & $1.75(1.09-2.81)$ & $1.71(1.02-2.87)$ & $1.15(0.75-1.77)$ & & \\
\hline $\begin{array}{l}\text { (Psycho)motor } \\
\text { difficulties }\end{array}$ & $2.22(1.35-3.65)$ & $2.41(1.38-4.17)$ & $2.60(1.42-4.76)$ & $1.16(0.68-1.99)$ & & \\
\hline Sleep problems & $1.37(1.06-1.78)$ & & & $1.31(1.05-1.63)$ & & \\
\hline Problems with eating & $1.33(1.05-1.69)$ & $1.34(1.02-1.73)$ & $1.28(1.02-2.87)$ & $1.38(1.08-1.76)$ & & \\
\hline $\begin{array}{l}\text { Social problems } \\
\text { in behavior }\end{array}$ & $1.84(1.23-2.73)$ & $1.65(1.04-2.60)$ & $1.73(1.06-2.84)$ & $1.25(0.83-1.88)$ & & \\
\hline $\begin{array}{l}\text { Attention hyperactivity } \\
\text { problems }\end{array}$ & $1.10(0.86-1.40)$ & & & $1.95(1.56-2,43)$ & $1.71(1.35-2.16)$ & $2.04(1.55-2.69)$ \\
\hline Externalizing problems & $1.22(0.96-1.55)$ & & & $1.47(1.18-1.84)$ & & \\
\hline Internalizing problems & $1.16(0.86-1.56)$ & & & $0.82(0.61-1.11)$ & & \\
\hline $\begin{array}{l}\text { Absence of parent- } \\
\text { reported positive } \\
\text { behavior }\end{array}$ & $1.43(1.13-1.81)$ & & & $1.36(1.09-1.70)$ & $1.36(1.06-1.75)$ & $1.25(0.95-1.64)$ \\
\hline $\begin{array}{l}\mathrm{ADHD} \text { or ASD problems in } \\
\text { adolescence }\end{array}$ & & & $6.48(4.85-8.66)$ & & & $6.85(5.10-9.20)$ \\
\hline
\end{tabular}

Criterion $p<0.2$ for inclusion in multiple logistic regression model

${ }^{\mathrm{a}}$ adj=adjusted for all other variables which are included in the multiple logistic regression model

${ }^{b}$ adj=adjusted for all other variables which are included in the multiple logistic regressionmodel including ADHD problems in ASD and ASD problems in ADHD groups

ASD and ADHD, report similar odds ratios (1.25-3.43) as we found, see St Pourcain, et al. (2011). The prospective and community-based nature of our study thus adds important information to what was already known.

Importantly, none of these studies used data from the $\mathrm{PCH}$ services, even though these services routinely follow the physical (diseases and growth) and psychosocial development of all children from birth on, in addition to screening for different disorders. Moreover, PCH services collect and register data according to a highly standardized format, including a number of objective parameters (e.g., birth weight, BMI, head circumference), therefore providing an 
outstanding setting for studying risk indicators in relatively unbiased general population samples.

Given our focus on the general community, it is important to note that we identified largely the same early indicators as have been reported for referred and selected high risk ASD and ADHD samples, i.e. pre- and perinatal factors (Smidts and Oosterlaan, 2007), early behavioral signs associated with ASD including impairments or delay in socialcommunicative development (Hartley et al. 2008; Ozonoff et al. 2010), early behavioral signs such as hyperactiveimpulsive and inattentive temperamental features (HirshfeldBecker et al. 2002; Smidts and Oosterlaan, 2007), motor, language and speech development (Hagberg et al. 2010; Landa and Garrett-Mayer, 2006; Loe et al. 2008), atypicalities in regulation functions related to eating (Werner and Dawson, 2005) and family adversity (Lara et al. 2009). This suggests that findings from selected samples may be generalized to community-based samples and vice versa, and emphasizes how useful the PCH setting can be for identifying and monitoring both mild and clinical ASD and ADHD.

The major strength of our study is the uniqueness of its design: its prospective nature, spanning many years from birth on, and its embedding in a routine $\mathrm{PCH}$ setting. Another strength is that we studied ASD and ADHD problems in tandem, therefore the first to report on generic and specific early childhood indicators. A further strength is our use of multiple indicators of varying types, as previous ASD or ADHD studies only used subsets of indicators. Recent overviews have shown that in most prognostic studies single rather than multiple indicators are investigated, but that multiple indicators provide better models (Burton and Altman, 2004; Riley et al. 2003). A final strength of this study is that the identification of ASD and ADHD problems was based on three ratings, each two-and-a-half years apart, thus reducing measurement error. Also, TRAILS constitutes a large sample with a high response rate, and we retrieved $\mathrm{PCH}$ files for the large majority of the participants.

Our study also has limitations, but insofar as these may have affected our results, they will all lead to underestimation of the predictive power of the PCH findings. First, children may have received effective treatment for their developmental problems between the ages of 4 and 11 . Second, children in our sample had a lower mean score on ASD and ADHD problems than the remaining of the sample for whom PCH files could not be retrieved, and also, as a result of the design of TRAILS, there were no cases of ASD with severe mental retardation in our study, while ASD problems are common in these children (de Bildt et al. 2003; Oeseburg et al. 2010). A related third issue is that some highly predictive early risk indicators are low prevalent and thus were not identified as indicators due to their low prevalence. This may, for instance, concern birth defects. Moreover, for some early risk indicators we lacked detailed information, for example, we knew if the mother smoked during pregnancy but not the daily dose of cigarettes. A fourth limitation is that the used questionnaires were not diagnostic tools performed by trained clinicians, and that we neither used semi-structured interviews. Previous studies, in particular where ASD is concerned, used (semi-)structured interviews which are less susceptible to measurement error and informant bias. Our questionnaires may have introduced additional measurement error due to interpretation problems by the parents. However, gold standard clinician-based interviews such as the ADI (Rutter et al., 2003), the K-SADS (Kaufman et al. 1997) and the PACS (Helverschou et al., 2009) are designed to pick up on only the severe cases within ASD, and ADHD patients. Considering the purpose of the current study they were of no use in our general population sample. Note that part of the measurement error was removed by repeated measurement of ASD and ADHD problems.

In conclusion, the community pediatric services are a useful setting for both research on early predictors of ASD and ADHD problems in general population samples and for the early detection of children at risk in routine care. From early childhood PCH-registered routine data of a large community based sample we identified largely the same early indicators of ASD and ADHD problems as have been reported for clinically referred ASD and ADHD samples. This shows that routine $\mathrm{PCH}$ can identify children at risk of both mild and clinical ASD and ADHD in early childhood. The community pediatric services may also play an important role in close monitoring of children identified in such a way, by administering in depth diagnostic instruments to further qualify their symptoms, and by providing early treatment if needed. Notwithstanding relatively modest differences, this may have a rather huge public health impact as these services cover the full population of children (Rose, 1992).

Acknowledgements TRAILS has been financially supported by various grants from the Netherlands Organization for Scientific Research (NWO), Social Sciences Council, the Sophia Foundation for Medical Research, the Dutch Ministry of Justice, and the participating universities. The authors thank the preventive child healthcare services in Drenthe, Friesland and Groningen for their permission to retrieve the PCH files from their archives. The authors are grateful to all the adolescents, their parents and teachers, who participated in this research, and to everyone who worked on this project and made it possible.

Declaration of Interest Prof. Buitelaar is a speaker for Lilly, Janssen Cilag and Medice. He is on the advisory board of Lilly, Janssen Cilag, UCB, Organon, Shire, Pfizer, Otsuka/BMS and Servier. He gives research support-IST to Lilly and Shire. He is also involved in clinical trials with Lilly and Janssen Cilag.

Prof. Verhulst is director of the Department of Child and Adolescent Psychiatry, Erasmus University Medical Center-Sophia Children's Hospital. This department publishes the Dutch translations of the Achenbach System of Empirically Based Assessment from which he receives remuneration. Dr. Jaspers, Dr. de Winter, Dr. Hartman and Prof. Reijneveld report no biomedical financial interests or potential conflicts of interest. 
Open Access This article is distributed under the terms of the Creative Commons Attribution License which permits any use, distribution, and reproduction in any medium, provided the original author(s) and the source are credited.

\section{References}

Achenbach, T. M., Dumenci, L., \& Rescorla, L. A. (2003). DSMoriented and empirically based approaches to constructing scales from the same item pools. Journal of Clinical Child and Adolescent Psychology, 32, 328-340.

Arnoudse-Moens, C. S., Weisglas-Kuperus, N., van Goudoever, J. B., \& Oosterlaan, J. (2009). Meta-analysis of neurobehavioral outcomes in very preterm and/or very low birth weight children. Pediatrics, 124, 717-728.

Burton, A., \& Altman, D. G. (2004). Missing covariate data within cancer prognostic studies: a review of current reporting and proposed guidelines. British Journal of Cancer, 91, 4-8.

Cole, T. J., Bellizzi, M. C., Flegal, K. M., \& Dietz, W. H. (2000). Establishing a standard definition for child overweight and obesity worldwide: international survey. BMJ, 320, 1240-1243.

Cole, T. J., Flegal, K. M., Nicholls, D., \& Jackson, A. A. (2007). Body mass index cut offs to define thinness in children and adolescents: international survey. BMJ, 335, 194.

Constantino, J. N., \& Todd, R. D. (2005). Intergenerational transmission of subthreshold autistic traits in the general population. Biological Psychiatry, 57, 655-660.

Courchesne, E. (2004). Brain development in autism: early overgrowth followed by premature arrest of growth. Mental Retardation and Developmental Disabilities Research Reviews, 10, 106-111.

Courchesne, E., Carper, R., \& Akshoomoff, N. (2003). Evidence of brain overgrowth in the first year of life in autism. Journal of the American Medical Association, 290, 337-344.

de Bildt, A., Sytema, S., Ketelaars, C., Kraijer, D., Volkmar, F., \& Minderaa, R. (2003). Measuring pervasive developmental disorders in children and adolescents with mental retardation: a comparison of two screening instruments used in a study of the total mentally retarded population from a designated area. Journal of Autism and Developmental Disorders, 33, 595-605.

de Winter, A. F., Oldehinkel, A. J., Veenstra, R., Brunnekreef, J. A., Verhulst, F. C., \& Ormel, J. (2005). Evaluation of non-response bias in mental health determinants and outcomes in a large sample of pre-adolescents. European Journal of Epidemiology, 20, $173-181$.

Goodlin-Jones, B. L., Tang, K., Liu, J., \& Anders, T. F. (2008). Sleep patterns in preschool-age children with autism, developmental delay, and typical development. Journal of the American Academy of Child and Adolescent Psychiatry, 47, 930-938.

Hagberg, B. S., Miniscalco, C., \& Gillberg, C. (2010). Clinic attenders with autism or attention-deficit/hyperactivity disorder: cognitive profile at school age and its relationship to preschool indicators of language delay. Research in Developmental Disabilities, 31, 1-8.

Hartley, S. L., Sikora, D. M., \& McCoy, R. (2008). Prevalence and risk factors of maladaptive behaviour in young children with Autistic Disorder. Journal of Intellectual Disability Research, 52, 819-829.

Hartman, C.A., Brunnekreef, J.A., De Sonneville, L.M.J., Buitelaar, J.K., Ormel, J., Minderaa', R.B., Hoekstra, P.J., Althaus, M. (2012). Deficient cognitive processing in children with autism spectrum problems from the general population. The TRAILS study. Submitted.

Hartman, C. A., Luteijn, E., Serra, M., \& Minderaa, R. (2006). Refinement of the Children's Social Behavior Questionnaire
(CSBQ): an instrument that describes the diverse problems seen in milder forms of PDD. Journal of Autism and Developmental Disorders, 36, 325-342.

Hattori, J., Ogino, T., Abiru, K., Nakano, K., Oka, M., \& Ohtsuka, Y. (2006). Are pervasive developmental disorders and attentiondeficit/hyperactivity disorder distinct disorders? Brain \& Development, 28, 371-374.

Helverschou, S. B., Bakken, T. L., \& Martinsen, H. (2009). The Psychopathology in Autism Checklist (PAC): A pilot study. Research in Autism Spectrum Disorders., 3(1), 179-195.

Hirshfeld-Becker, D. R., Biederman, J., Faraone, S. V., Violette, H., Wrightsman, J., \& Rosenbaum, J. F. (2002). Temperamental correlates of disruptive behavior disorders in young children: preliminary findings. Biological Psychiatry, 51, 563-574.

Huisman, M., Oldehinkel, A. J., de Winter, A. F., Minderaa, R. B., de Bildt, A., Huizink, A. C., Verhulst, F. C., \& Ormel, J. (2008). Cohort profile: the Dutch 'TRacking Adolescents' Individual Lives' Survey'; TRAILS. International Journal of Epidemiology, 37, 1227-1235.

Jacobusse, G., Van Buuren, S., \& Verkerk, P. H. (2006). An interval scale for development of children aged 0-2 years. Statistics in Medicine, 25, 2272-2283.

Kaufman, J., Bismaher, B., Brent, D. A., Rao, U., Flynn, C., Moreci, P., Williamson, D., \& Ryan, N. (1997). Schedule for Affective Disorders and Schizophrenia for School-Aged Children - Present and Lifetime Version (K-SADS-PL): initial reliability and validity data. Journal of the American Academy of Child and Adolescent Psychiatry, 36, 980-988.

Kolevzon, A., Gross, R., \& Reichenberg, A. (2007). Prenatal and perinatal risk factors for autism: a review and integration of findings. Archives of Pediatrics \& Adolescent Medicine, 161, 326-333.

Landa, R., \& Garrett-Mayer, E. (2006). Development in infants with autism spectrum disorders: a prospective study. Journal of Child Psychology and Psychiatry, 47, 629-638.

Lara, C., Fayyad, J., de Graaf, R., Kessler, R. C., Aguilar-Gaxiola, S., Angermeyer, M., Demytteneare, K., de Girolamo, G., Haro, J. M., Jin, R., Karam, E. G., Lepine, J. P., Mora, M. E., Ormel, J., Posada-Villa, J., \& Sampson, N. (2009). Childhood predictors of adult attention-deficit/hyperactivity disorder: results from the World Health Organization World Mental Health Survey Initiative. Biological Psychiatry, 65, 46-54.

Levy, F., Hay, D. A., McStephen, M., Wood, C., \& Waldman, I. (1997). Attention-deficit hyperactivity disorder: a category or a continuum? Genetic analysis of a large-scale twin study. Journal of the American Academy of Child and Adolescent Psychiatry, 36, 737-744.

Loe, I. M., Balestrino, M. D., Phelps, R. A., Kurs-Lasky, M., ChavesGnecco, D., Paradise, J. L., \& Feldman, H. M. (2008). Early histories of school-aged children with attention-deficit/hyperactivity disorder. Child Development, 79, 1853-1868.

Loe, I. M., \& Feldman, H. M. (2007). Academic and educational outcomes of children with ADHD. Journal of Pediatric Psychology, 32, 643-654.

Losh, M., Adolphs, R., Poe, M. D., Couture, S., Penn, D., Baranek, G. T., \& Piven, J. (2009). Neuropsychological profile of autism and the broad autism phenotype. Archives of General Psychiatry, 66, $518-526$.

Mouridsen, S. E., Rich, B., \& Isager, T. (2008). Body mass index in male and female children with pervasive developmental disorders. Pediatrics International, 50, 569-571.

Nijmeijer, J. S., Arias-Vasquez, A., Rommelse, N. N., Altink, M. E., Anney, R. J., Asherson, P., Banaschewski, T., Buschgens, C. J., Fliers, E. A., Gill, M., Minderaa, R. B., Poustka, L., Sergeant, J. A., Buitelaar, J. K., Franke, B., Ebstein, R. P., Miranda, A., Mulas, F., Oades, R. D., Roeyers, H., Rothenberger, A., Sonuga-Barke, E. J., Steinhausen, H. C., Faraone, S. V., Hartman, 
C. A., \& Hoekstra, P. J. (2010). Identifying Loci for the Overlap Between Attention-Deficit/Hyperactivity Disorder and Autism Spectrum Disorder Using a Genome-wide QTL Linkage Approach. Journal of the American Academy of Child and Adolescent Psychiatry, 49, 675-685.

Oeseburg, B., Groothoff, J. W., Dijkstra, G. J., Reijneveld, S. A., \& Jansen, D. E. (2010). Pervasive developmental disorder behavior in adolescents with intellectual disability and co-occurring somatic chronic diseases. Research in Developmental Disabilities, 31, 496-501.

Ozonoff, S., Iosif, A., Baguio, F., Cook, I. C., Hill, M. M., Hutman, T., Rogers, S. J., Rozga, A., \& Sangha, S. (2010). A prospective study of the emergence of early behavioral signs of autism. Journal of the American Academy of Child and Adolescent Psychiatry, 49, 256-266.

Piven, J. (2002). Genetics of Personality: The Example of the Broad Autism Phenotype. In J. Benjamin, R. P. Ebstein, \& R. H. Belmaker (Eds.), Molecular Genetics and the Human Personality (pp. 43-62). Washingtom, DC: American Psychiatric Publishing.

Ploeger, A., Raijmakers, M. E., van der Maas, H. L., \& Galis, F. (2010). The association between autism and errors in early embryogenesis: what is the causal mechanism? Biol. Psychiatry, 67, 602-607.

Reiersen, A. M., Constantino, J. N., Volk, H. E., \& Todd, R. D. (2007). Autistic traits in a population-based ADHD twin sample. Journal of Child Psychology and Psychiatry, 48, 464-472.

Riley, R. D., Abrams, K. R., Sutton, A. J., Lambert, P. C., Jones, D. R., Heney, D., \& Burchill, S. A. (2003). Reporting of prognostic markers: current problems and development of guidelines for evidence-based practice in the future. British Journal of Cancer, 88, 1191-1198.

Rogers, S. J., \& Vismara, L. A. (2008). Evidence-based comprehensive treatments for early autism. Journal of Clinical Child and Adolescent Psychology, 37, 8-38.

Rommelse N. N., Geurts H. M., Franke B., Buitelaar J. K., Hartman C. A. (2011). A review on cognitive and brain endophenotypes that may be common in autism spectrum disorder and attention-deficit/ hyperactivity disorder and facilitate the search for pleiotropic genes. Neuroscience and Biobehavioral Reviews, 35, 1363-1396.

Ronald, A., Edelson, L. R., Asherson, P., \& Saudino, K. J. (2010). Exploring the relationship between autistic-like traits and ADHD behaviors in early childhood: findings from a community twin study of 2-yearolds. Journal of Abnormal Child Psychology, 38, 185-196.

Rose, G. (1992). The strategy of preventive medicine. Oxford: Oxford University Press.

Rutter, M., Le Couteur, A., \& Lord, C. (2003). ADI-R. Autism diagnostic interview revised. Manual. Los Angeles: Western Psychological Services.

Salmeron, P. A. (2009). Childhood and adolescent attention-deficit hyperactivity disorder: Diagnosis, clinical practice guidelines, and social implications. Journal of the American Academy of Nurse Practitioners, 21, 488-497.
Schendel, D. E., Autry, A., Wines, R., \& Moore, C. (2009). The co-occurrence of autism and birth defects: prevalence and risk in a population-based cohort. Child Neurol: Dev. Med.

Simonoff, E., Pickles, A., Charman, T., Chandler, S., Loucas, T., \& Baird, G. (2008). Psychiatric disorders in children with autism spectrum disorders: prevalence, comorbidity, and associated factors in a population-derived sample. Journal of the American Academy of Child and Adolescent Psychiatry, 47, 921-929.

Smidts, D. P., \& Oosterlaan, J. (2007). How common are symptoms of ADHD in typically developing preschoolers? A study on prevalence rates and prenatal/demographic risk factors. Cortex, 43, $710-717$.

Stilp, R. L. H., Gernsbacher, M. A., Schweigert, E. K., Arneson, C. L., \& Goldsmith, H. H. (2010). Genetic Variance for autism screening items in an unselected sample of toddler-age twins. Journal of the American Academy of Child and Adolescent Psychiatry, 49, 267-276.

St Pourcain, B., Mandy, W. P., Heron, J., Golding, J., Smith, G. D., \& Skuse, D. H. (2011). Links between co-occuring socialcommunication and hyperactive-inattentive trait trajectories. Journal of the American Academy of Child and Adolescent Psychiatry, 50, 892-902.

Sung, V., Hiscock, H., Sciberras, E., \& Efron, D. (2008). Sleep problems in children with attention-deficit/hyperactivity disorder: prevalence and the effect on the child and family. Archives of Pediatrics \& Adolescent Medicine, 162, 336-342.

't Hart-Kerkhoffs, L. A., Jansen, L. M., Doreleijers, T. A., Vermeiren, R., Minderaa, R. B., \& Hartman, C. A. (2009). Autism Spectrum Disorder Symptoms in Juvenile Suspects of Sex Offenses. The Journal of Clinical Psychiatry, 70, 266-272.

Thapar, A., Harrington, R., \& McGuffin, P. (2001). Examining the comorbidity of ADHD-related behaviours and conduct problems using a twin study design. The British Journal of Psychiatry, 179, 224-229.

Werner, E., \& Dawson, G. (2005). Validation of the phenomenon of autistic regression using home videotapes. Archives of General Psychiatry, 62, 889-895.

Yirmiya, N., \& Charman, T. (2010). The prodrome of autism: early behavioral and biological signs, regression, peri- and post-natal development and genetics. Journal of Child Psychology and Psychiatry, 51, 432-458.

Zwaigenbaum, L., Bryson, S., Lord, C., Rogers, S., Carter, A., Carver, L., Chawarska, K., Constantino, J., Dawson, G., Dobkins, K., Fein, D., Iverson, J., Klin, A., Landa, R., Messinger, D., Ozonoff, S., Sigman, M., Stone, W., Tager-Flusberg, H., \& Yirmiya, N. (2009). Clinical assessment and management of toddlers with suspected autism spectrum disorder: insights from studies of high-risk infants. Pediatrics, 123, 1383-1391.

Zwaigenbaum, L., Bryson, S., Rogers, T., Roberts, W., Brian, J., \& Szatmari, P. (2005). Behavioral manifestations of autism in the first year of life. International Journal of Developmental Neuroscience, 23, 143-152. 